\title{
Monitoring of biophysicochemical changes in a silty clay soil contaminated with LNAPLS
}

\author{
E. Martinho ${ }^{\text {a,* }}$, M.M. Abreu ${ }^{\text {b }}$, A. Oliveira ${ }^{\text {c }}$, F. Alegria ${ }^{\text {d }}$, M.E. Pampulha ${ }^{\text {c }}$ \\ a Departamento de Engenharia de Engenharia Civil, Arquitectura e Georrecursos, Centro de Recursos Naturais e Ambiente, Instituto Superior Técnico, \\ Technical University of Lisbon (TULisbon), Av. Rovisco Pais, 1049-001 Lisboa, Portugal \\ b Universidade Técnica de Lisboa, Instituto Superior de Agronomia, Unidade de Investigação de Química Ambiental, Tapada da Ajuda, 1349-017 Lisboa, Portugal \\ c Laboratório de Microbiologia, Instituto Superior de Agronomia, Technical University of Lisbon (TULisbon), Tapada da Ajuda, 1349-017 Lisboa, Portugal

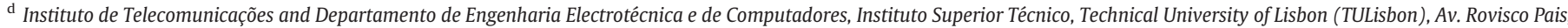 \\ 1049-001 Lisboa, Portugal
}

\section{A R T I C L E I N F O}

\section{Article history:}

Received 20 June 2011

Received in revised form 27 July 2012

Accepted 8 January 2013

Available online 9 February 2013

\section{Keywords:}

Soil

Contamination

Hydrocarbons

Biodegradation

Resistivity/induced polarization

\begin{abstract}
A B S T R A C T
The interdependence between time domain induced polarization measurements at uncontaminated and artificially contaminated soil samples with diesel and biophysicochemical alterations caused by diesel degradation was investigated during 12 months. The research was performed on a slightly alkaline soil, with high content of organic matter $(148 \mathrm{~g} / \mathrm{kg}$ ) and silty clay texture. Soil clay mineralogy was mainly composed of plagioclase, amphibole, biotite, interstratified mica-smectite, goethite and some vestigial kaolinite. A decrease on resistivity and induced polarization (IP) in contaminated soil was observed during the 12 months. This reduction on geoelectrical parameters was related to: 1) the increase on the electrolyte conductivity; 2) the increase on interfacial surface area, as result of biotite transformation and weathering of other ferromagnesian minerals and 3) a slight increase in soil aggregation, caused by diesel-degrading microorganisms (a significant increase of the numbers of specific carbon degraders was observed). After 4 months, the IP response was lowest in the contaminated soil which was explained by inhibition of the cation exchange capacity due to two possible processes: 1 ) clay particles coating by organic molecules and 2 ) attachment of microbial cells (biofilms) to clay particles and/or soil aggregates. The results suggest that the content and mineralogy of the clay fraction as well as the aggregation state of the soils contaminated with LNAPL's affect the IP response. This response is a diagnostic of the biophysicochemical alterations occurring during diesel degradation as a result of biological activity.
\end{abstract}

(c) 2013 Elsevier B.V. All rights reserved.

\section{Introduction}

Soil and groundwater contamination by crude oils or refinery products remains a significant environmental problem. In recent years, geophysical, geochemical and numerous microbiological studies (e.g., Abdel Aal et al., 2006; Allen et al., 2007; Atekwana et al., 2005; Cozzarelli et al., 2001; Personna et al., 2008) have been carried out with the aim of understanding the complex relationships between geological materials and these pollutants, in order to proceed to the clean-up of many contaminated sites.

Geophysical studies have revealed high conductivities of aged oil plumes (Atekwana et al., 2004; Sauck, 2000; Sauck et al., 1998) although oil hydrocarbons are electrically resistive. Several mechanisms are being pointed out as causes for the high measured conductivity, and most of them are related to the indigenous microorganisms and

\footnotetext{
* Corresponding author. Tel.: + 351 218417510; fax: + 351218400806.

E-mail addresses: emar@mail.ist.utl.pt (E. Martinho), manuelaabreu@isa.utl.pt (M.M. Abreu), adnpoliveira@isa.utl.pt (A. Oliveira), falegria@lx.it.pt (F. Alegria), mepampulha@isa.utl.pt (M.E. Pampulha).
}

microbial activity in hydrocarbon contaminated sites. These include changes in pore fluid chemistry due to enhanced minerals weathering caused by acids produced as byproducts of the hydrocarbon degradation (Atekwana et al., 2005), increase in solid phases surface area or pore clogging resulting from growth of microbial cells attached to sediment grains in biofilms or precipitation of metal sulfides at cell or sediment grains surface (Abdel Aal et al., 2004, 2006, 2009; Davis et al., 2006; Ntarlagiannis et al., 2005; Slater et al., 2007; Williams et al., 2005) as well as redox processes (Naudet and Revil, 2005). Also, the presence of microbial nanowires (highly conductive pili) produced by some bacteria species as Schewanella oneidensis (Gorby et al., 2006) might increase subsurface conductive levels in certain geomicrobiological environments.

Numerous publications, including those cited above, have analyzed microbial community structures and activities and their relationships with geophysical signatures in sedimentary aquifer formations (fine to medium sand and gravel) or in laboratory experiments using sand columns. However, superficial soil systems, where contamination with light nonaqueous phase liquids frequently occurs, can be a dynamic quite different system where the contaminants biodegradation can lead to changes in the physicochemical properties in other ways than those 
occurring in sedimentary systems, as reported by Martinho et al. (2010). This study, conducted on a soil developed on granitic rocks with a loamy texture and where soil particle aggregation occurred, a decrease of IP effect was observed unlike the results obtained by Abdel Aal et al. (2006) and Ntarlagiannis and Ferguson (2009). In soil systems, variations in the solid phase arrangement can occur by disaggregation or aggregation of the soil particles/small aggregates promoted by both biological and physical-chemical processes. As a consequence, the new structural state of the soil can change the networks of pores within and between the aggregates influencing the movement of air and water and the activities of soil organisms (Brady and Weil, 2008). Therefore, the geoelectrical behavior of soils contaminated with hydrocarbons can be influenced by soil physical parameters such as aggregate size distribution and bulk porosity. Because of those contradicting results, in the present study were investigated the biophysicochemical changes occurred during natural hydrocarbons degradation (nutrients were not used to stimulate microbial activity) on a silty clay soil developed on basalt and therefore with different physical and chemical characteristics of the previous soil developed on granitic rocks. The main objective was to contribute for the understanding of the bioremediation approaches and ways for their monitoring in different types of hydrocarbons contaminated soils.

\section{Materials and methods}

The soil material used in the experiment was taken in the superficial layer, at a depth of 0-30 cm, of a forest soil developed on basalt. The sampled soil was stored in dark plastic bags at room temperature after air-dried and sieving at $2 \mathrm{~mm}$. Fraction $<2 \mathrm{~mm}$ was used for physical and chemical characterization and for laboratory experiments. Water-holding capacity of this soil was evaluated according to the classic methodology (Forster, 1998) after soil saturation and excess water has been drained by gravity until downward movement has materially ceased.

The adapted experimental procedure included the preparation of sixteen soil samples - eight uncontaminated and eight contaminated samples. The uncontaminated soil samples were prepared by mixing soil with water in order to obtain the soil moisture corresponding to $50 \%$ of the water-holding capacity of the soil. The contaminated soil samples were prepared by first mixing the soil and diesel oil (7\%) and then adding water in order to also achieve $50 \%$ of the soil water-holding capacity. Each sample suitably homogenized was placed in a sample holder. The accuracy to $50 \%$ of the soil water-holding capacity was related to the establishment of the most favorable conditions to the development of soil microorganisms considering that this is a silty clay soil. The properties of diesel used for soil contamination are given in Table 1.

Sixteen identical columns made of polyvinyl chloride (PVC) cylindrical tube, $50 \mathrm{~cm}$ long and with an inner diameter of $19 \mathrm{~cm}$, were used as sample holders (Fig. 1). Two sets of samples were made, each with four uncontaminated and four contaminated samples. The incubation time

Table 1

Properties of diesel oil used for contamination.

\begin{tabular}{llccc}
\hline Properties & & Results & \multicolumn{2}{l}{ Limits } \\
\cline { 3 - 4 } & & & Min & Max \\
\hline Density at $15{ }^{\circ} \mathrm{C}$ & $\mathrm{kg} / \mathrm{m}^{3}$ & 838.0 & 820 & 845 \\
Total sulfur & $\mathrm{mg} / \mathrm{kg}$ & 25.6 & & 50.0 \\
Cetane number & & 51.0 & 51.0 & \\
Flash point (proc.A) & ${ }^{\circ} \mathrm{C}$ & 70 & $>55$ & \\
CFPP & ${ }^{\circ} \mathrm{C}$ & -11 & & -10 \\
Recovered at $250{ }^{\circ} \mathrm{C}$ & $\%(\mathrm{v} / \mathrm{v})$ & 34 & & 65 \\
Recovered at $350{ }^{\circ} \mathrm{C}$ & $\%(\mathrm{v} / \mathrm{v})$ & 93 & 85 & \\
$95 \%$ recovered & ${ }^{\circ} \mathrm{C}$ & 358 & & 360 \\
Lubricity & $\mathrm{micrometer}$ & 207 & & 460 \\
Water & $\%(\mathrm{~m} / \mathrm{m})$ & 0.006 & & 0.020 \\
FAME content & $\%(\mathrm{v} / \mathrm{v})$ & 2.8 & & 5 \\
\hline
\end{tabular}

was 4 months for one set (C1T, C2T, C7T and C15T-uncontaminated samples; C4DT, C9DT, C12DT and C16DT-contaminated samples) and 12 months for another set (C3T, C6T, C8T and C14T-uncontaminated samples; C5DT, C11DT, C10DT and C13DT-contaminated samples). The soil moisture content ( $50 \%$ of the soil water-holding capacity) of the samples was kept constant during the experiment time (the samples were weighed twice a week and water was added, from the top of the column, to maintain the samples weight constant). Electrical measurements were made of 4 in 4 months in two uncontaminated and two contaminated samples. These measurements were made of 4-by-4 months because the biodegradation of hydrocarbons is slow. Almost identical conductivity profiles were obtained during measurements in 16 different months in a petroleum-contaminated site (Jonathan et al., 2007). After 4 and 12 months from the experiment starting, the soil samples of each set were collected from the sample holders at two depths (0-20 and $20-40 \mathrm{~cm}$ far from the surface) for physical, chemical and microbiological analysis.

\subsection{Soil analysis}

The original soil sample ( $<2 \mathrm{~mm}$ fraction) was characterized as follows: particle size distribution by sieving and sedimentation; $\mathrm{pH}$ in a water suspension $(1: 2.5, \mathrm{~m}: \mathrm{v})$; total organic carbon (TOC) by potassium dichromate oxidation; cation exchange capacity (CEC) and exchangeable cations by $1 \mathrm{~mol} / \mathrm{L}$ ammonium acetate at $\mathrm{pH} 7$ (Póvoas and Barral, 1992); iron from iron oxides by De Endredy (1963) method for total fraction and Schwertmann (1964) method for the non-crystalline fraction.

Iron from iron oxides, CEC and exchangeable cations as well as, TOC, were also analysed in composite contaminated and uncontaminated soil samples after 12 months of incubation. Soil pH was also measured in the four replicates of each set of experiments (after 4 and 12 months of incubation). The clay fraction $(<2 \mu \mathrm{m})$ was separated from soil samples by water dispersion and sedimentation following Stokes law. Mineralogical analyses were undertaken in basally oriented preparations of clay samples separated from the initial soil and in composite contaminated and uncontaminated soil samples after 12 months of incubation, by $\mathrm{X}$ ray diffraction analysis (XRD) using $\mathrm{Cu} \mathrm{K} \alpha$ radiation.

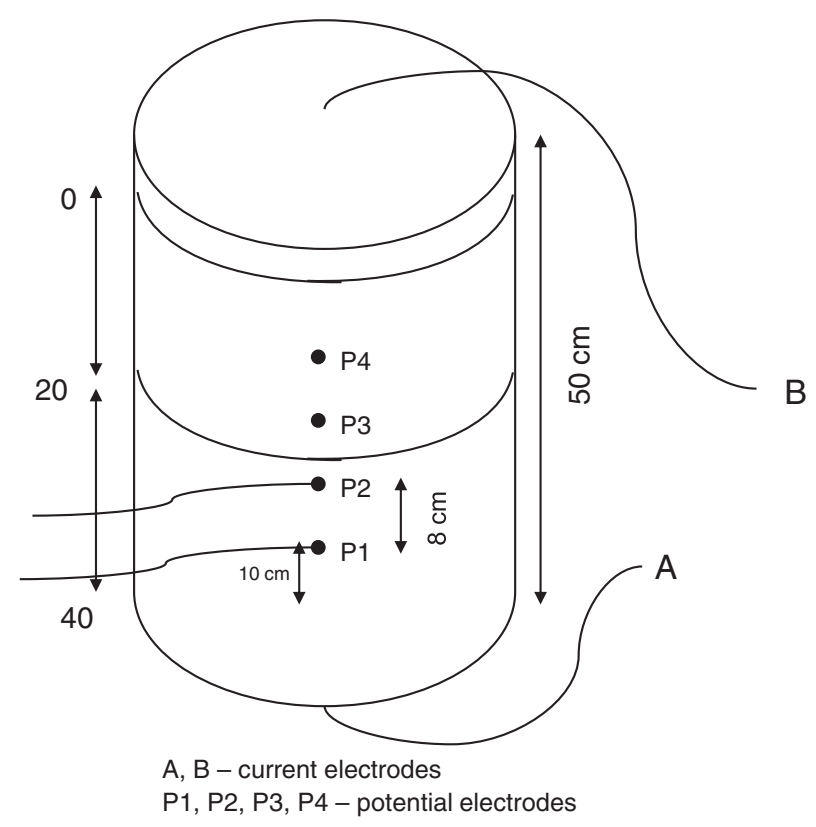

Fig. 1. PVC tube sample holder for electrical measurements, where the graphite and nonpolarizable $\mathrm{Cu} / \mathrm{CuSO} 4$ electrodes, used as current and potential electrodes, respectively, are incorporated. 
Undisturbed soil samples for bulk density determination were collected in metal cylinders $6 \mathrm{~cm}$ in diameter and $8 \mathrm{~cm}$ high in the field (0-30 cm depth) and in each PVC tube for the two depths (0-20 and $20-40 \mathrm{~cm}$ far from the surface) and for both sets of experiments. Samples for bulk density determination were also collected immediately after the water and diesel oil addition to soil. Two replicas for each sampling were made. After bulk density calculation $\left(105^{\circ} \mathrm{C}\right.$ dry weight of soil/volume of soil) soil porosity was estimated assuming $2.52 \mathrm{~g} / \mathrm{cm}^{3}$ as the particle density for this soil. This value was obtained after correction of the average particle density of soils $\left(2.65 \mathrm{~g} / \mathrm{cm}^{3}\right)$ taking into account the soil organic matter content (Brady and Weil, 2008).

Soil aggregate distribution was determined in the soil samples collected immediately after the water and diesel oil addition and in all the soil samples (from two depths) of both sets of experiments (after 4 and 12 months of incubation) by sieving following the procedure described in Martinho et al. (2010). Five replicates for each sampling were made.

Data analysis was carried out by univariate statistic and the comparison between contaminated and uncontaminated samples was performed through a one-way ANOVA procedure and Tukey test $(p<0.05)$ using the statistical programme SPSS v13.0.

The content in diesel range oil (DRO) was measured in three of the contaminated samples of one of the sets (including C12DT) after 4 months and another set (including C13DT) after 12 months, at two depths (0-20 and $20-40 \mathrm{~cm})$. The DRO was also measured in one sample (SD0-T) immediately after the contamination. The DRO was determined by gas chromatography/mass spectrometry method.

\subsection{Induced polarization measurements}

The induced polarization measurements (resistivity, polarizability and chargeability) were obtained in four (C12DT, C13DT, C14T and C15T) of the sixteen columns by using a six-electrode technique. An automated system was built to carry out the measurements with as much ease as possible while at the same time minimizing operator bias and Human errors. The system is centered on a personal computer (PC) running LabVIEW, a graphical programming language created by National Instruments. The PC is connected through a digital interface (IEEE-488) to a current source (model 6220 from Keithley Instruments) allowing it to control the value of the current applied to the soil sample (between electrodes A and B as depicted in Fig. 1), and a digital voltmeter (model 2000 from Keithley Instruments) to measure the voltage between different potential electrodes (P1 through P4 as depicted in Fig. 1). Specially designed graphite porous electrodes and non-polarizable $8 \mathrm{~cm}$ long $\mathrm{Cu} / \mathrm{CuSO}_{4}$ electrodes were as current and potential electrodes, respectively (Alegria et al., 2009).

The current source used has a settling time (to $1 \%$ of its final value) of $100 \mu \mathrm{s}(\mathrm{KI}, 2005)$ which is fast enough for the application at hand where the time constants involved are in the order of milliseconds to seconds. The input impedance of the voltmeter is $1 \mathrm{M} \Omega$ in parallel with less than $100 \mathrm{pF}$. These values are high and low enough, respectively, such that the connection of the voltmeter to the soil sample does not affect its electrical behavior. The application running on the PC is described in more detail in Alegria et al. (2009).

The measurements were performed at three locations along the columns (between electrode pairs P1-P2, P2-P3, and P3-P4) at zero and after 4 months of incubation time on uncontaminated (C14T and C15T) and contaminated (C12DT and C13DT) samples and 8 and 12 months later as well on samples C14T and C13DT. Twenty cycles were used with current changes between 4 and $5 \mathrm{~mA}$ and with a pulse duration of $4 \mathrm{~s}$. The voltage waveforms obtained are similar to the one presented in Figure 3 of Martinho et al. (2010).

In any measurement and derived quantity there are errors due to physical phenomena and technological limitations of the instruments used. Some of these errors are systematic and known and can, therefore, be corrected, while others are random or systematic but unknown and cannot be corrected. The modern approach is to assign a probability distribution to those sources of uncertainty and define an interval (confidence interval) inside which one expects to find the correct value of the quantity with a given probability (confidence level). These procedures are recommended in a document called "Guide for the Expression of Uncertainty in Measurement" (BIPM et al., 1995) which is often referred to by its abbreviation GUM.

There are numerous sources of uncertainty in the estimation of the values of resistivity and polarizability. One of the main sources of uncertainty, in the case of resistivity estimation, is the accuracy with each the current source sets the value of the current applied to the sample. Another source of uncertainty that affects the estimation of the two parameters mentioned above is the voltmeter's accuracy.

In the following we will compute the confidence interval half-length for the estimation of resistivity and polarizability using the typical procedure recommended in the GUM and taking into account only the sources of uncertainty related to the instruments accuracy. The stated accuracy for the current source for the range used $(20 \mathrm{~mA})$ is $0.05 \%$ of the reading plus $10 \mu \mathrm{A}(\mathrm{KI}, 2005)$. For the highest value of current used $(5 \mathrm{~mA})$ this leads to an accuracy of $12.5 \mu \mathrm{A}$. Since nothing is said in the instrument's manual about the probability distribution of this specification we will assume a uniform distribution with a half-length equal to that accuracy $(12.5 \mu \mathrm{A})$. The standard deviation of that distribution, which is usually called "standard uncertainty" in the language of the GUM $\left(u_{\mathrm{I}}\right)$, is the half-length divided by the square-root of 3 . One thus have $u_{\mathrm{I}}=7.217 \mu \mathrm{A}$.

The voltage measurement accuracy, for the $1 \mathrm{~V}$ range used, is $30 \mathrm{ppm}$ of the reading plus $7 \mathrm{ppm}$ of the range (ppm means parts per million) (KI, 1999). For a typical value of primary voltage $\left(V_{\mathrm{p}}\right)$ of $1 \mathrm{~V}$ this leads to an accuracy of $37 \mu \mathrm{V}$ and a standard uncertainty $\left(u_{V p}\right)$ of $21.36 \mu \mathrm{V}$ (again using a uniform probability distribution). In the case of the secondary voltage $\left(V_{s}\right)$ which typically is around $10 \mathrm{mV}$, one has an accuracy of $7.3 \mu \mathrm{V}$ and a standard uncertainty of $4.215 \mu \mathrm{V}\left(u_{V s}\right)$.

Since the resistivity is given by

$\rho=\frac{V_{\mathrm{p}}}{I} L$

the combined uncertainty of the current source and the voltmeter in the case of computing the resistivity is, using the law of uncertainty propagation recommended in the GUM,

$u_{\rho}=\sqrt{\left(\frac{L}{I}\right)^{2} u_{V_{\mathrm{p}}}^{2}+\left(\frac{V_{\mathrm{p}} L}{I^{2}}\right)^{2} u_{I}^{2}}$

Using, as an example the values of sample length of $10 \mathrm{~cm}$, applied current of $5 \mathrm{~mA}$ and primary voltage of $1 \mathrm{~V}$ leads to a resistivity combined uncertainty of $0.029 \Omega \mathrm{m}$. The half-length of the confidence interval (called expanded uncertainty) can be computed by multiplying the combined uncertainty by the coverage factor $(K)$ for a given probability function. Choosing, as typically is done, a normal distribution and a confidence level of 95\% leads to coverage factor of 2.58 (BIPM et al., 1995) and a confidence interval half-width of $0.074 \Omega \mathrm{m}$ for the resistivity.

In the case of the polarizability, given by

$\eta=\frac{V_{\mathrm{s}}}{V_{\mathrm{p}}}$

the compounded uncertainty may be computed using

$u_{\eta}=\sqrt{\left(\frac{1}{V_{\mathrm{p}}}\right)^{2} u_{V_{\mathrm{s}}}^{2}+\left(\frac{V_{\mathrm{s}}}{V_{\mathrm{p}}^{2}}\right)^{2} u_{V_{\mathrm{p}}}^{2}}$ 
Table 2

Half-width of the confidence interval for a 95\% confidence level for the resistivity and polarizability (Type A evaluation of uncertainty).

\begin{tabular}{|c|c|c|c|c|c|}
\hline & \multirow[b]{2}{*}{ Samples } & \multicolumn{4}{|c|}{ Time (months) } \\
\hline & & 0 & 4 & 8 & 12 \\
\hline \multirow[t]{12}{*}{ Resistivity $(\Omega \mathrm{m})$} & C12DT-P1P2 & 1.37 & 2.63 & & \\
\hline & C12DT-P2P3 & 0.54 & 1.06 & & \\
\hline & C12DT-P3P4 & 8.13 & 0.72 & & \\
\hline & C13DT-P1P2 & 2.3 & 2.92 & 1.37 & 0.52 \\
\hline & C13DT-P2P3 & 0.52 & 0.49 & 1.03 & 1.03 \\
\hline & C13DT-P3P4 & 1.55 & 1.55 & 3.07 & 0.72 \\
\hline & C14T-P1P2 & 0.83 & 1.63 & 1.65 & 3.56 \\
\hline & C14T-P2P3 & 0.93 & 0.46 & 1.94 & 1.03 \\
\hline & C14T-P3P4 & 5.29 & 4 & 3.3 & 6.01 \\
\hline & C15T-P1P2 & 0.67 & 1.08 & & \\
\hline & C15T-P2P3 & 1.06 & 0.88 & & \\
\hline & C15T-P3P4 & 1.32 & 1.78 & & \\
\hline \multirow[t]{12}{*}{ Polarizability (mv/V) } & C12DT-P1P2 & 0.08 & 0.13 & & \\
\hline & C12DT-P2P3 & 0.03 & 0.03 & & \\
\hline & C12DT-P3P4 & 0.65 & 0.36 & & \\
\hline & C13DT-P1P2 & 0.1 & 0.18 & 0.05 & 0.83 \\
\hline & C13DT-P2P3 & 0.05 & 0.08 & 0.08 & 0.03 \\
\hline & C13DT-P3P4 & 0.08 & 0.13 & 0.23 & 0.72 \\
\hline & C14T-P1P2 & 0.02 & 0.03 & 0.02 & 0.15 \\
\hline & C14T-P2P3 & 0.03 & 0.02 & 0.03 & 0.01 \\
\hline & С14T-P3P4 & 0.15 & 0.15 & 0.1 & 0.05 \\
\hline & C15T-P1P2 & 0.01 & 0.01 & & \\
\hline & C15T-P2P3 & 0.02 & 0.08 & & \\
\hline & С15T-Р3Р4 & 0.03 & 0.52 & & \\
\hline
\end{tabular}

which leads to an example value of $4.22 \mu \mathrm{V} / \mathrm{V}$. Again, the expanded uncertainty (half-width of confidence interval), considering a normal distribution and $95 \%$ confidence level, is approximately $0.01 \mathrm{mV} / \mathrm{V}$.

This type of evaluation of uncertainty is called a type B evaluation in opposition to the type A evaluation which consists in repeating the measurements and computations of derived quantities several times and computing the standard deviation of the values obtained. In our case we repeated the measurements 10 times and computed the half-width of the confidence interval for a 95\% confidence level (coverage factor of 2.58, considering a normal distribution). The results presented (Table 2) for different samples and time intervals from the beginning of the trial show higher values of half-width of confidence interval than those presented earlier and obtained through a type B evaluation. The reason is that the mathematical computations of uncertainty presented (type B evaluation) considered only the instruments' accuracy as sources of uncertainty. There are, nonetheless, other sources of uncertainty affecting the results obtained like the displacement of connecting cables, their change of resistance with environment conditions and the contact between the electrodes and the soil samples, for example. The type B evaluation presented earlier allows us to state that the accuracy of the instruments used is sufficient for the purposes at hand and that if one would want to improve on the results' uncertainty one should look at those other sources of uncertainty.

\subsection{Microbiological methods}

Dehydrogenase activity was determined by the method of Tabatabai (1982) and for soil adenosine-5'-triphosphate (ATP) published methods (Oades and Jenkinson, 1979; Tate and Jenkinson, 1982) with some modifications (Oliveira and Pampulha, 2006).

Numbers of specific carbon degraders in control and contaminated soil was based on the most probable number (MPN) technique described in Martinho et al. (2010).

\section{Results}

\subsection{Soils}

Physical and chemical properties of the soil are given in Table 3. The soil has a silty clay texture (69\% of particles $<20 \mu \mathrm{m}$ ), is slightly alkaline and with high total organic carbon (TOC) content. The total soil porosity (\% pore space) in field conditions for the surface layer $(0-20 \mathrm{~cm})$ is given in Table 3 and its value is in accordance with the soil structure and texture, and organic matter content of the soil.

The cation exchange capacity of the soil is high, as a consequence of the great organic matter content $(148 \mathrm{~g} / \mathrm{kg}$ soil $\mathrm{OM}=\mathrm{TOC} \times 1.724)$ and clay content ( $420 \mathrm{~g} / \mathrm{kg}$ soil) as well as the type of clay minerals (mainly $2: 1$ phyllosilicates). Calcium and magnesium are the dominant exchangeable cations and the negative surface charges of the soil colloids were saturated.

Soil mineralogy of the clay fraction $(<2 \mu \mathrm{m})$ was mainly composed of plagioclase, amphibole, biotite, interstratified mica-smectite, goethite and some vestigial kaolinite. X-ray diffraction analysis of soils after incubation during 12 months in both contaminated and uncontaminated samples showed, comparing to the beginning of the experiment, some differences in mineralogical composition. During the time span of incubation biotite transformation occurs leading to the increase of the interstratified mica-smectite mineral where the smectite layers present low charge. This transformation is more intense in the contaminated samples where the characteristic XRD peak of mica $(1.0 \mathrm{~nm})$ almost disappears. In these samples the kaolinite structure also showed some disorder. Weathering of the ferromagnesian minerals (biotite and amphibole) has been occurred, with iron(III) release as shown by the increase of the iron oxides concentrations, both in contaminated and uncontaminated samples, especially for the non-crystalline fraction (Table 3 ) which showed an increase of $38 \%$.

Table 3

Physical and chemical properties of the soil (fraction $<2 \mathrm{~mm}$ ) at time zero and after 12 months of incubation (contaminated and uncontaminated soil samples).

\begin{tabular}{|c|c|c|c|c|}
\hline Parameters & & UC0 (0 months) & UC (12 months) & C (12 months) \\
\hline \multirow[t]{5}{*}{ Particle size distribution $(\mathrm{g} / \mathrm{kg})$} & Coarse sand $(0.2<\varnothing<2 \mathrm{~mm}$ & 150 & & \\
\hline & Fine sand $(0.02<\varnothing<0.2 \mathrm{~mm})$ & 163 & & \\
\hline & Silt $(0.002<\varnothing<0.02 \mathrm{~mm})$ & 267 & & \\
\hline & Clay $(\varnothing<0.002 \mathrm{~mm})$ & 420 & & \\
\hline & Texture & Silty clay & & \\
\hline Porosity (\%) (field conditions) & & 48 & & \\
\hline Total organic carbon $(\mathrm{g} / \mathrm{kg})$ & & 85.8 & 72.2 & 87.8 \\
\hline \multirow[t]{3}{*}{ Iron $(\mathrm{g} / \mathrm{kg}$ ) from iron oxides } & Crystalline & 13.88 & 17.78 & 14.64 \\
\hline & Non-crystalline & 4.91 & 7.85 & 7.97 \\
\hline & Non-crystalline (\% of total) & 26 & 31 & 35 \\
\hline $\mathrm{CEC}\left(\mathrm{cmol}_{\mathrm{c}} / \mathrm{kg}\right)$ & & 67.3 & 60.56 & 57.66 \\
\hline Exchangeable cations & $\mathrm{Ca}$ & 56.40 & 52.56 & 46.24 \\
\hline \multirow{3}{*}{$\left(\mathrm{cmol}_{\mathrm{c}} / \mathrm{kg}\right)$} & $\mathrm{Mg}$ & 11.11 & 10.51 & 9.64 \\
\hline & K & 0.53 & 0.43 & 0.33 \\
\hline & $\mathrm{Na}$ & 0.19 & 0.40 & 0.43 \\
\hline
\end{tabular}

UCO - uncontaminated initial sample; UC - uncontaminated sample; C - contaminated sample; CEC - Cation Exchange Capacity. 
Soil $\mathrm{pH}$ for contaminated and uncontaminated samples (both depths) showed a decrease over the 12 months time span, while no significant differences were observed after 4 months of incubation for the same samples (Table 4).

The determined soil porosity (total porosity) of the samples at each time of collection did not show any evolution after the two incubation periods. The results obtained for time zero for contaminated and uncontaminated samples are not significantly different to those found at 4 and 12 months of incubation and for both depths (Fig. 2A). Comparing these results with the porosity determined in the undisturbed samples (field porosity), an increase of $\approx 16 \%$ was observed, which can be the result of soil structure destruction due to soil sieving and manipulation for water and diesel addition.

Total organic carbon decreases after 12 months of incubation in the uncontaminated soil, while in the contaminated samples slightly increase due to diesel addition and probably to its incomplete degradation by soil microorganisms. Cation exchange capacity decreases after incubation, especially in the contaminated samples. Also the exchangeable cations ( $\mathrm{Ca}, \mathrm{Mg}$ and $\mathrm{K}$ ) decreased after 12 months of incubation (Table 3 ).

Soil aggregate distribution for uncontaminated and contaminated samples is shown in Fig. $2 \mathrm{~B}$ and $\mathrm{C}$, respectively. At time zero, uncontaminated and contaminated soil samples showed a similar pattern on the aggregates distribution. The finer aggregate classes (between $<0.05$ and $0.2 \mathrm{~mm}$ ) correspond to $13.5 \%$ and $11 \%$ of the total, whereas the coarser aggregate classes (between 2 and $>2 \mathrm{~mm}$ ) attain 50 and $55 \%$ of the whole soil for uncontaminated and contaminated samples, respectively.

Along the incubation time for contaminated and uncontaminated samples as well as for all aggregate classes no significant differences were obtained between soil layers (0-20 and 20-40 cm). During the 12 months of incubation, the two coarser fractions of aggregates showed a decrease which was greater $(\approx 12 \%)$ for the uncontaminated soil samples. However, from 4 to 12 months of incubation the contaminated samples presented a slight increase of $2 \%$ in the aggregates classes between 1 and $2 \mathrm{~mm}$. The observed disaggregation, especially on the aggregates fraction $>2 \mathrm{~mm}$, was followed by the increase of $11 \%$ (uncontaminated samples) and 7\% (contaminated samples) on the aggregates whose dimensions lie between 0.2 and $1 \mathrm{~mm}$. No differences were observed on the aggregate classes $<0.05 \mathrm{~mm}$ and $0.1-0.05 \mathrm{~mm}$ between time zero, 4 and 12 months of incubation. The aggregates between 0.2 and $0.1 \mathrm{~mm}$ showed a slight increase (2.5\%) at 4 months of incubation for both samples, but at the end of the experiment no significant differences were observed when compared with time zero results.

\subsection{Diesel range oil}

Fig. 3a and b show the aliphatic and aromatic compounds fraction in the soil at time zero (background), 4 and 12 months after contamination for 0-20 and 20-40 cm layers, respectively. A decrease in compounds fraction was observed along time being more significant between 4 and 12 months. For those mentioned maturation times,

\section{Table 4}

Soil $\mathrm{pH}$ for contaminated (C) and uncontaminated (UC) soil samples (0-20 and 20-40 cm depths) at time zero (UCO and CO) and after 4 and 12 months of incubation. (mean \pm standard deviation, $n=8$ ).

\begin{tabular}{|c|c|c|c|}
\hline & \multicolumn{3}{|c|}{ Time (months) } \\
\hline & 0 & 4 & 12 \\
\hline $\mathrm{UC}(0-20 \mathrm{~cm})$ & $7.58 \pm 0.06^{\mathrm{a}}$ & $7.45 \pm 0.07^{\mathrm{a}}$ & $7.04 \pm 0.34^{b}$ \\
\hline $\mathrm{UC}(20-40 \mathrm{~cm})$ & $* 7.58 \pm 0.06^{\mathrm{a}}$ & $7.39 \pm 0.20^{a}$ & $7.04 \pm 0.28^{b}$ \\
\hline$C(0-20 \mathrm{~cm})$ & $7.43 \pm 0.03^{a}$ & $7.65 \pm 0.08^{a}$ & $6.74 \pm 0.22^{\mathrm{b}}$ \\
\hline$C(20-40 \mathrm{~cm})$ & $* 7.43 \pm 0.03^{\mathrm{a}}$ & $7.57 \pm 0.10^{\mathrm{a}}$ & $6.71 \pm 0.18^{b}$ \\
\hline
\end{tabular}

* soil pH at time zero correspond to the same soil sample without depth differences. Different letters in same row indicate significant differences $(p<0.05)$.
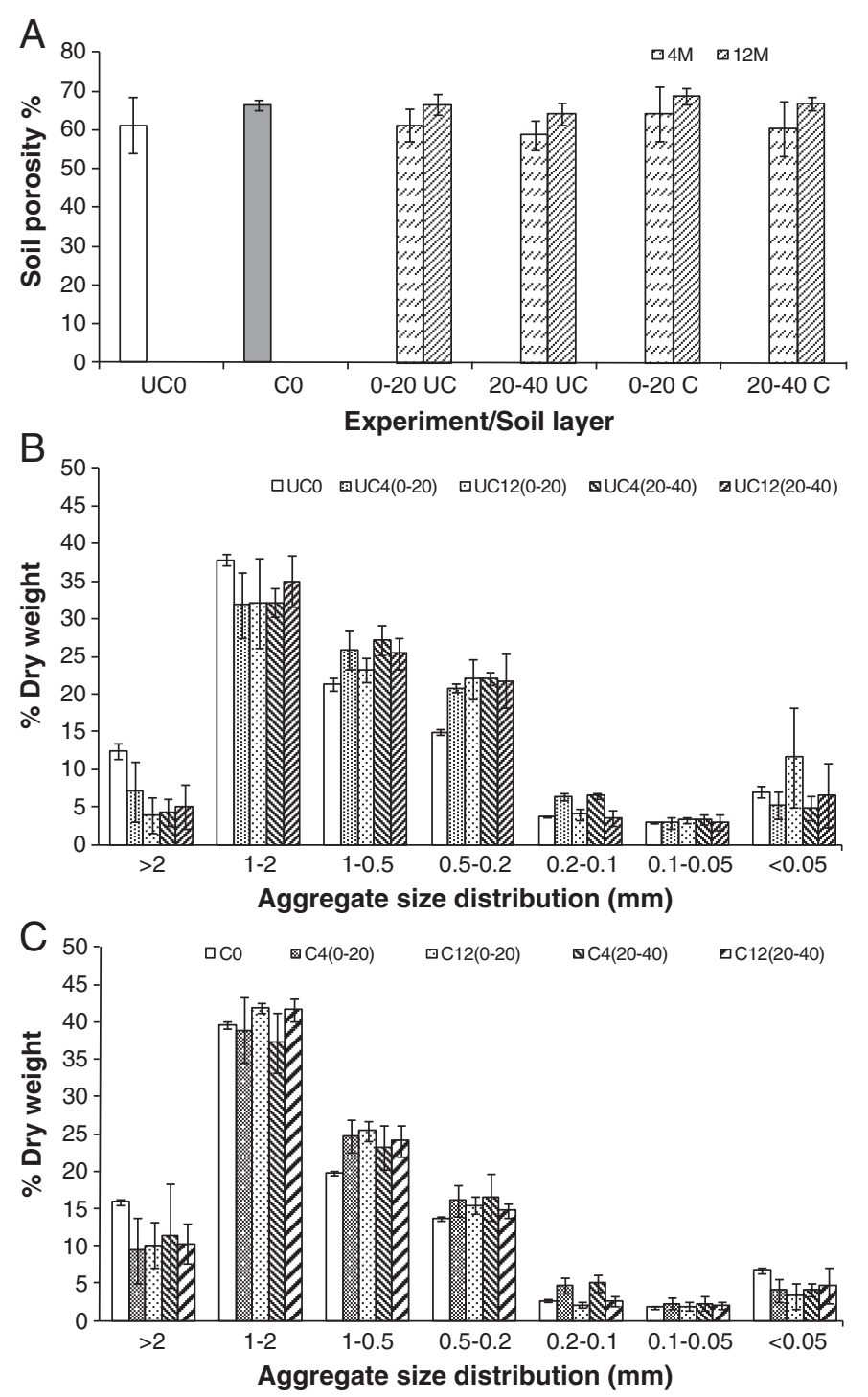

Fig. 2. Soil physical parameters: (A) bulk soil porosity percentage (mean \pm standard deviation, $n=8$ ); (B) aggregate size distribution for uncontaminated soil samples (\% dry weight) (mean \pm standard deviation, $n=20$ ); (C) aggregate size distribution for diesel-contaminated soil samples (\% dry weight) (mean \pm standard deviation, $n=20$ ). $\mathrm{UCO}=$ uncontaminated soil at time zero; $\mathrm{C}=$ contaminated soil at time zero; $4 \mathrm{M}=$ soil at 4 months of incubation; $12 \mathrm{M}=$ soil at 12 months of incubation; $0-20$ and 20-40 (depth in centimetres of sample collection in tube sample holder); UC= uncontaminated soil; C = diesel-contaminated soil; UC4 and UC12 - uncontaminated soil at 4 and 12 months of incubation, respectively; C4 and C12 - diesel-contaminated soil at 4 and 12 months of incubation, respectively.

no differences were observed in the amount of compounds between the two layers. The results also showed that 12 months were not enough time for a complete degradation of diesel.

\subsection{Induced polarization}

Fig. $4 \mathrm{~A}$ and $\mathrm{B}$ shows the temporal changes of the measured IP parameters (resistivity and polarizability, respectively) for uncontaminated and contaminated samples. The chargeability data are not presented because the values and the behavior over time are similar to the polarizability whose SD of the measurements was lowest. In uncontaminated sample C14T, for P3-P4 depth, the IP parameters were very difficult to obtain and are anomalous; therefore, for this depth, the polarizability from 4 months of incubation was not plotted in the graph (Fig. 4B). As can be seen in Table 2, the uncertainty is highest for this section of the column. 

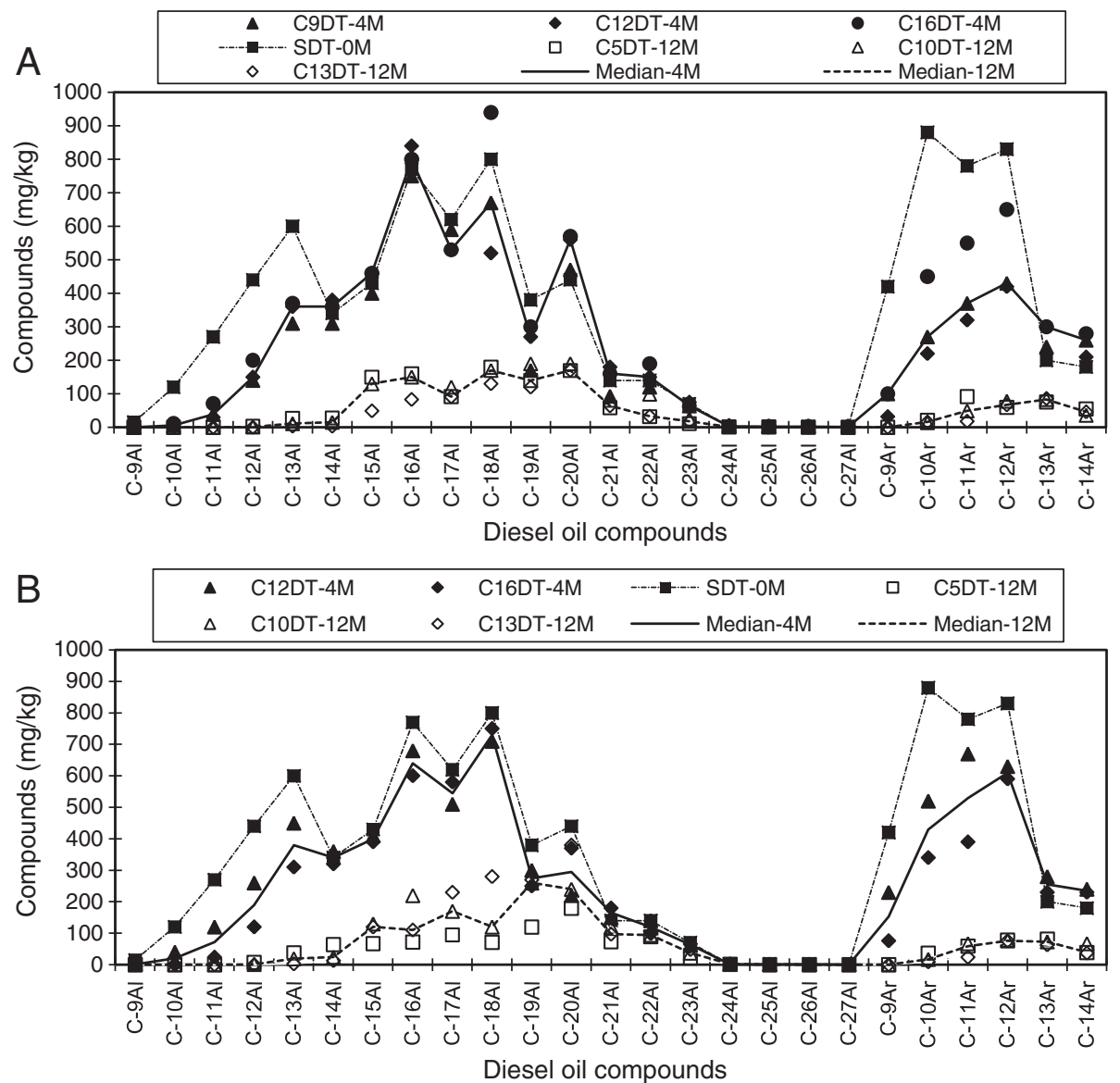

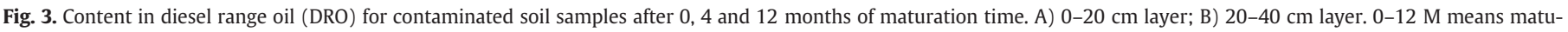
ration time from 0 to 12 months; $\mathrm{Al}$ and $\mathrm{Ar}$ indicate aliphatic and aromatic hydrocarbons, respectively.

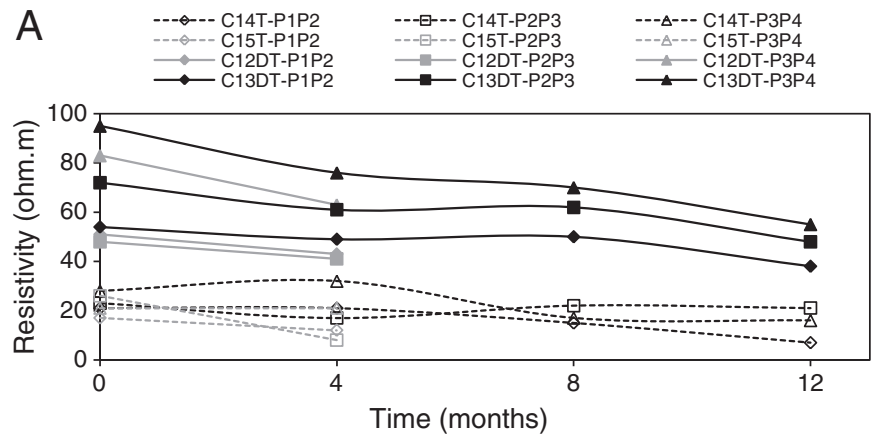

B $\quad---\diamond--$ C14T-P1P2 $----A--$ C14T-P3P4 $\quad--\diamond--$ C15T-P1P2

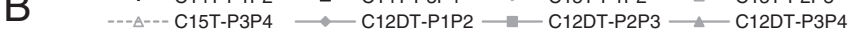
$\longrightarrow$ C13DT-P1P2 $\longrightarrow$ C13DT-P2P3 — C13DT-P3P4 ---曰--- C14T-P2P3

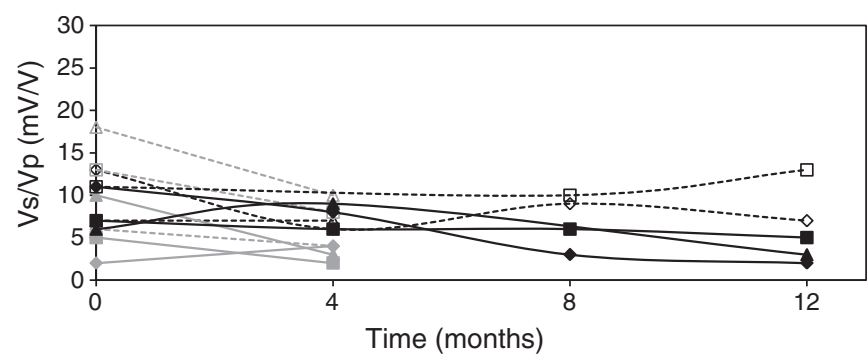

Fig. 4. IP results at different locations of columns for uncontaminated and contaminated soil samples (e.g., C14T-P1P2 and C13DT-P1P2 means the uncontaminated sample C14T and contaminated sample C13DT respectively, measured between P1P2 potential electrodes). A) Resistivity data for uncontaminated and contaminated soil samples; B) Polarizability data for uncontaminated and contaminated soil samples.
Lowest resistivity $(\sim 20 \Omega \mathrm{m})$ characterizes the uncontaminated samples for each measured depth (P1-P2, P2-P3 and P3-P4) and significant changes were not observed over time. The low resistivity values are related to soil texture (silty clay), as the soil has high clay content $(420 \mathrm{~g} / \mathrm{kg}$ of soil), as well as the clay minerals (2:1 phyllosilicates) characteristics (high surface area and relatively high charge density). In contrast, the resistivity increased with diesel contamination $(\sim 50-95 \Omega \mathrm{m})$ and the observed values are different for each depth, mainly at the beginning of the experiment, which may be due to some instability of the system related to the presence of the diesel (with the contamination). In contaminated samples, the resistivity decreased from top to bottom of the column $\left(\rho_{\mathrm{P} 3-\mathrm{P} 4}>\rho_{\mathrm{P} 2-\mathrm{P} 3}>\rho_{\mathrm{P} 1-\mathrm{P} 2}\right)$. Over time, the behavior of resistivity is similar for the three depths; a decrease is observed, except between 4 and 8 months where there is a slight increase. The contamination did not cause significant variations in polarizability. However, after 4 months the magnitude of this parameter is slightly lowest in the contaminated samples and, although not very marked, a decrease over time could be observed. The decrease in geoelectrical parameters can be related to diesel degradation. However, after 12 months the resistivity of contaminated samples remained above those of the uncontaminated samples. This result is consistent with the DRO results, which showed a significant degradation, but not complete, of the diesel.

\subsection{Microbiology}

Results of the microbiological analysis are summarized in Table 5. Control soil (uncontaminated) showed an increase in the number of hydrocarbon-degrading microorganisms, which may be attributed to the soil treatment (watering, incubation) along the assay period. 
However, the diesel addition strongly increased the number of diesel degraders, which reaches its maximum after 12 months of incubation. These results are in agreement with the data presented in Fig. 3, demonstrating a higher diesel removal rate after 12 months. A significant difference between the two layers was also observed. In the $20-40 \mathrm{~cm}$ layer, the number of hydrocarbon degraders was greater in both soil samples (contaminated and uncontaminated), but it was more evident in the contaminated soil. When comparing contaminated and uncontaminated soil, experimental data of soil dehydrogenase activity (DHA) indicate that microbial activity was lower in the contaminated soil but increased between 4 and 12 months in contrast to the uncontaminated soil where a decrease was observed during the same time. The DHA decreased with soil depth, presenting in both contaminated and uncontaminated soil samples lower values in the $20-40 \mathrm{~cm}$ layer. In contrast, diesel soil contamination increased ATP content in both layers, which also showed an increase in this parameter with incubation time.

\section{Discussion}

The structure of the soil microbial community seems to diverge quickly from that of the control soil after the diesel addition, since 4 months after the contamination, the MPN of diesel degraders increased about 275 and $400 \%$ in the $0-20$ and $20-40 \mathrm{~cm}$ layers, respectively (Table 5). After 12 months this discrepancy was more evident. This strong relation between microbial counts and hydrocarbon degradation has been reported by other authors (Heinaru et al., 2005; Lin et al., 2010). The larger number of diesel degraders in contaminated soil samples shows that microbial population has acclimated to the experimental conditions.

The results also indicate that the studied soil contains a healthy indigenous population capable to initiate and support bioremediation processes, in agreement with the results of diesel biodegradation (Fig. 3). The microorganisms have the potential to modify the physical structure and porosity of the soil by promoting particle aggregation (Degans, 1997; Six et al., 2004). However, despite the high increase of the number of hydrocarbon-degrading microorganisms in contaminated samples, only a slight increase in soil aggregation, mainly aggregate classes between 1 and $0.2 \mathrm{~mm}$, was observed (Fig. 2C). This slight change in the soil particles aggregation was not translated by the increase on soil porosity, which is not statistically different along all the incubation time (Fig. 2A). However, it seems that there was a slight tendency to the porosity increase between 4 and 12 months with the possible formation of some larger pores between the larger aggregates. As was already referred, this slight increase in porosity is not significant and therefore did not caused large variations in the formation factor (Orellana, 1982) and consequently in the resistivity. Uncontaminated samples also showed the same behavior as contaminated samples; no significant differences on soil porosity and a slight increase on soil particles aggregation (increase in the same classes of aggregates). As shown in Fig. 4A), this increase was not enough to cause variations in resistivity, which remains constant over incubation time. The decrease in resistivity of the contaminated samples observed over time can be mainly related to the decrease in the electrolyte resistivity caused by the decrease of aliphatic and aromatic compounds (Fig. 3), by mineral weathering carried out by microorganisms during degradation of hydrocarbons, as well as the formation of other solid phases. In fact, after soil incubation, during 12 months, the XRD analysis showed some differences in mineralogical composition, either in uncontaminated or contaminated samples, but being more intense in the last samples. These results are in agreement with some research that links the increase of conductivity observed at hydrocarbon-impacted sites to mineral weathering caused by organic acids produced by biological activity (Atekwana et al., 2004, 2005; Cassidy et al., 2001; Sauck, 2000). In the studied soil, the biotite was transformed into smectite which present largest surface area and CEC. In addition, iron from amphibole and biotite weathering was oxidized and hydrolyzed to originate iron hydrous-oxides. These iron oxides show, frequently, very small size (nanometric scale) and some of them are none or poorly crystalline ( $35 \%$ of the total iron oxides in contaminated soil samples) presenting, consequently, large specific surface area. The increase of solid phases $(<2 \mu \mathrm{m})$ with large surface area as well as the cations concentration in soil solution due to weathering processes might contribute to the increase of the conductivity as reported by several authors (Kemna et al., 2004; Lesmes and Friedman, 2005).

In this study, the $\mathrm{pH}$ values measured on contaminated samples were lower than on uncontaminated samples after 12 months (Table 4) which is also in agreement with the observed increase in ATP content and microbial degraders enumeration on contaminated soil. The ATP content can be used to measure the overall microbial activity of the soil and their behavior seems to be closely related with the microbial biomass carbon (Marin et al., 2005). The microbial biomass was highest at all collecting periods in the contaminated soil, which is also in agreement with microbial diesel degraders enumeration and with the observed decrease in exchangeable cations (Ca, Mg and $\mathrm{K}$, Table 3). This decrease in the soil exchangeable cations was higher in the contaminated samples as a consequence of the increased microbial biomass. Dehydrogenase activity (DHA) which is related with microbial activity has also been used to measure the catabolic activities in soil (Marin et al., 2005). Since biological oxidation of organic compounds is generally a dehydrogenation process, catalyzed by dehydrogenase enzymes (Balba et al., 1998), it could be expected an increase of DHA, reflecting the increase in hydrocarbon degraders. Nevertheless, in this study, DHA was lowest in diesel contaminated soil (Table 5). The decrease in labile carbon sources and the lower bioavailability of the remaining diesel fractions such as cycloalkanes or cycloparaffins (Martienssen et al., 2003) may be a reason leading to the drop of dehydrogenase activity. Other studies (Speir and Ross, 2002) also indicate that, at moderate levels of hydrocarbon contamination, some enzyme activities declined, as was stated in the present work.

In the contaminated samples, the resistivity decreased from the top to the bottom of the column $\left(\rho_{\mathrm{P} 3-\mathrm{P} 4}>\rho_{\mathrm{P} 2-\mathrm{P} 3}>\rho_{\mathrm{P} 1-\mathrm{P} 2}\right)$. Despite the slightly highest ATP content and number of hydrocarbon-degrading microorganisms in the $20-40 \mathrm{~cm}$ layer (P1-P2 section), no differences in the amount of aliphatic and aromatic compounds (DRO results)

Table 5

Effects of diesel oil soil contamination on microbiological parameters after 4 and 12 months of incubation, in 0-20 and 20-40 cm layers.

\begin{tabular}{|c|c|c|c|c|c|c|}
\hline & \multicolumn{2}{|c|}{$\begin{array}{l}\text { Dehydrogenase activity ( } \mu \mathrm{g} \text { TPF } \mathrm{g}^{-} \\
\text {dry soil) } \\
\end{array}$} & \multicolumn{2}{|c|}{ ATP content ( $\mu \mathrm{g} \mathrm{g}^{-1}$ dry soil) } & \multicolumn{2}{|c|}{$\begin{array}{l}\text { MPN of culturable diesel oil } \\
\text { degraders }\left(\times 10^{6} \mathrm{~g}^{-1} \text { dry soil }\right)\end{array}$} \\
\hline & 4 months & 12 months & 4 months & 12 months & 4 months & 12 months \\
\hline \multicolumn{7}{|l|}{ 0-20 cm layer } \\
\hline Uncontaminated soil & $77 \pm 8$ & $74 \pm 6$ & $0.41 \pm 0.08$ & $0.48 \pm 0.09$ & $4.8 \pm 0.5$ & $10.2 \pm 1.7$ \\
\hline Contaminated soil & $57 \pm 7$ & $60 \pm 5$ & $0.63 \pm 0.15$ & $0.69 \pm 0.16$ & $13.2 \pm 2$ & $121 \pm 15.3$ \\
\hline \multicolumn{7}{|l|}{$20-40 \mathrm{~cm}$ layer } \\
\hline Uncontaminated soil & $70 \pm 6$ & $60 \pm 6$ & $0.47 \pm 0.10$ & $0.42 \pm 0.11$ & $7.7 \pm 1.0$ & $13.7 \pm 2.5$ \\
\hline Contaminated soil & $53 \pm 7$ & $55 \pm 6$ & $0.71 \pm 0.14$ & $0.83 \pm 0.19$ & $32.7 \pm 4.6$ & $147 \pm 19.1$ \\
\hline
\end{tabular}


between the two layers over time were observed (Fig. 3A, B). The $\mathrm{pH}$ values were also similar in the two layers (Table 4). Then, the decrease in resistivity along the column may be related to the increase of the soil moisture at depth. During the hydrocarbon degradation, variations in the solid phases arrangement of soils by disaggregation or aggregation of the soil particles/small aggregates can occur, promoted by both biological and physical-chemical processes. This can lead to a change of the networks of pores within and between the aggregates influencing the movement of air and water (Brady and Weil, 2008). In this study, the movement of water (which was added at the top of the column to maintain constant the soil moisture content) along the soil column may have been facilitated in the contaminated samples. In fact, in these soil samples the observed disaggregation in the coarsest aggregates $(>2 \mathrm{~mm})$ after diesel addition was smaller than those observed in the uncontaminated samples (Fig. 2B, C). The smallest disaggregation in the diesel amended soil, as well as the high content in the aggregates class $1-2 \mathrm{~mm}$ can be responsible by a slight pore size increase (and larger number of interconnected pores) in the contaminated samples. As a consequence, the soil moisture content will be highest with depth increase, which is consistent with the behavior observed in the measured resistivity.

The polarization effect in petroleum hydrocarbons contaminated sediments is an issue that despite having attracted the attention of many researchers in recent years is not well understood. Several research works carried out in sandy sedimentary rocks (Abdel Aal et al., 2006, 2009; Davis et al., 2006; Ntarlagiannis and Ferguson, 2009) showed an enhanced of the IP response related with microbial processes, namely accumulation of microbial cells (biofilms) on the sandy mineral surface. However, according to several authors (e.g. Kemna et al., 2004; Vanhala, 1997), the mineralogy (namely clay mineralogy) and grain diameter of the materials, and the composition of the electrolyte are the main parameters that affect the IP. The amount and type of clay minerals and their interaction with organic molecules cause changes in the polarization effect because in geologic materials where clay particles are present, the IP effect is also due to the membrane polarization (Reynolds, 1997; Sharma, 1997). These interactions have not been studied in the above mentioned works, performed in sandy sedimentary rocks.

In contrast with the obtained results for the resistivity, the diesel contamination of the studied soil did not cause significant changes in IP effect (Fig. 4B). For these amended soil samples, at time zero and after 4 months of incubation, the polarizability values did not differ from the values measured in uncontaminated soil samples. This may be related to the fact that the contamination at the beginning of the experiment (till 4 months of incubation) did not have caused significant variations on porosity and soil aggregation (Fig. 2A, B, C). Variations on soil aggregation have implications for the effect of IP. This parameter is highest in sediments which have disseminated clay particles (> specific surface area) and weak when clays are compacted (Sharma, 1997; Vanhala, 1997). In the present study, the smallest soil particles $(<0.05 \mathrm{~mm})$ are mainly included in large aggregates (aggregate classes between 0.2 and $2 \mathrm{~mm}$ ) which correspond to more than $70 \%$ of the total of the soil aggregates/particles (Fig. 2B).

The decrease of the polarizability values observed in the contaminated sample after 4 to 12 months of incubation time can be related to several processes that occurred in the soil column. The decrease on electrolyte resistivity, the slight increase on soil aggregation, the increase of the interstratification process biotite to smectite, and the iron oxides concentration increase, especially the non-crystalline fraction, together with the amphibole weathering, as already mentioned, contributed to the increase of the electrical conductivity of the medium; a decrease of electrical resistivity was observed (Fig. 4A), which caused a decrease in the IP effect (Fig. 4B). According to several authors (Keevil and Ward, 1962; Klein and Sill, 1982; Marshall and Madden, 1959; Vinegar and Waxman, 1984), in sediments with clay particles in which the IP effect is due to membrane polarization, as is the case of the present study, the increase in electrical conductivity leads to a decrease in IP because the ion conduction is facilitated. The increase on soil aggregation led to a decrease of the interfacial surface area of the clay, with consequent decrease of the CEC (Kemna et al., 2004), which may also have contributed to the decrease of the IP. As shown in Fig. 4B, the polarizability values between 4 and 12 months were lowest in the contaminated sample although a total degradation of hydrocarbons had not occurred, as can be seen from DRO results (Fig. 3). This can be explained by two mechanisms: 1) a process whereby organic molecules coat the surface of clay particles, inhibiting the cation-exchange processes, as explained by Olhoeft $(1985) ; 2$ ) by attachment of microbial cells (biofilms) to clay particlesand/or soil aggregates, as suggested by several researchers (Abdel Aal et al., 2004, 2006, 2009; Davis et al., 2006), also inhibiting the cation-exchange processes (blocking the cation exchange sites and consequently the electric double layer). These hypotheses are in agreement with the DHA (DHA is lowest in diesel contaminated soil) and CEC (after 12 months, the CEC in the contaminated soil was lower than in the uncontaminated soil and, especially, than in the initial soil (Table 3)).

This study shows that the physical and chemical properties of the soil and its mineralogy and the occurred weathering processes during incubation time have influence on the biophysicochemical behavior of the soil during hydrocarbons degradation with implications in the IP effect. Comparing the results of this study with those obtained by Martinho et al. (2010), it can be concluded that the soil/diesel initial mixture did not cause changes in polarizability, which was not observed by the reported study wherein the addition of diesel increased this parameter. The initial increase in polarizability in the soil developed on granitic rock (loam texture) was due to a significant increase in soil disaggregation caused by the addition of diesel, which was not observed in the silty clay soil. In the present study, despite the observed decrease in polarizability after 4 months, its value was lower than that measured in the uncontaminated sample. This result is in oposition to that obtained for loamy soil, where after 12 months of incubation the polarizability was greater in the contaminated soil. An increase in the amount of hydrocarbon degraders was observed in both studies, however, in the present study, only a slight increase on particle soil aggregation and porosity occurred while in the previous one was observed a significant increase in aggregation and a decrease on total soil porosity. This difference in soil structure and porosity is translated by the behavior of electrical parameters in both soils, especially in the first 8 months of experience. Both studies show that different mechanisms may be involved in soil/diesel mixture during the biodegradation and that those mechanisms depend on the characteristics of the soil.

\section{Conclusions}

The results from this study provide evidence that IP time domain measurements, specifically polarizability measurements, can be used to evaluate the polarization mechanisms in soil/organic mixtures during hydrocarbon biodegradation as a result of biological activity. The clay particles coating by organic molecules and/or biofilm formation on mineral grain surfaces or soil aggregates seem to be the cause of the cation exchange process inhibition (with consequent decrease in IP effect) and decrease of microbial activity (DHA). In the contaminated soil, the decrease on electrolyte resistivity, caused by the decrease of aliphatic and aromatic compounds, the slight increase on soil aggregation and the increase of the specific surface, due to mineral transformations and weathering of the ferromagnesian minerals, contributed to the observed decrease, with time, in geoelectrical parameters. These results further increase the understanding on the processes involved in the hydrocarbons degradation. The biophysicochemical alterations occurred in soils contaminated with hydrocarbons during biodegradation depend on the physical 
and chemical properties of the soils and their mineralogy, causing changes in the IP effect.

\section{Acknowledgements}

This work was developed under the POCI/ECM/58768/2004 Project and funded by FCT, POCI 2010 Program and FEDER (European Communitarian Funds). The authors wish to thank to Galp Energy (Portugal) by diesel oil used in contamination of the samples and Dr. F. G. Monteiro for XRD analysis.

\section{References}

Abdel Aal, G.Z., Atekwana, E., Slate, r L.D., Atekwana, E.A., 2004. Effects of microbial processes on electrolytic and interfacial electrical properties of unconsolidated sediments. Geophysical Research Letters 31, L12505. http://dx.doi.org/10.1029/ 2004GL020030.

Abdel Aal, G.Z., Slater, L.D., Atekwana, E., 2006. Induced-polarization measurements on unconsolidated sediments from a site of active hydrocarbon biodegradation. Geophysics 71, H13-H24.

Abdel Aal, G.Z., Atekwana, E., Radzikowski, S., Rossbach, S., 2009. Effect of bacterial adsorption on low frequency electrical properties of clean quartz sands and ironoxide coated sands. Geophysical Research Letters 36, L04403. http://dx.doi.org/ 10.1029/2008GL036196.

Alegria, F.C., Martinho, E., Almeida, F., 2009. Measuring soil contamination with the time domain induced polarization method using LabVIEW. Measurement 42 , 1082-1091. http://dx.doi.org/10.1016/j.measurement.2009.03.015.

Allen, J.P., Atekwana, E.A., Atekwana, E.A., Duris, J.W., Werkema, D.D., Rossbach, S., 2007. The microbial community structure in petroleum-contaminated sediments corresponds to geophysical signatures. Applied and Environmental Microbiology 73, 2860-2870.

Atekwana, E., Werkema, D.D., Duris, J.W., Rossbach, S., Atekwana, E.A., Sauck, W.A., Cassidy, D.P., Means, J., Legall, F.D., 2004. In-situ apparent conductivity measurements and microbial population distribution at a hydrocarbon-contaminated site. Geophysics 69, 56-63.

Atekwana, E.A., Atekwana, E., Legall, F.D., Krishnamurthy, R.V., 2005. Biodegradation and mineral weathering controls on bulk electrical conductivity in a shallow hydrocarbon contaminated aquifer. Journal of Contaminant Hydrology 80, 149-167.

Balba, M.T., Al-Awadhi, N., Al-Daher, R., 1998. Bioremediation of oil-contaminated soil: microbiological methods for feasibility assessment and field evaluation. Journal of Microbiological Methods 32, 155-164.

BIPM, IEC, IFCC, ISO, IUPAC, IUPAP, OIML, 1995. Guide to the Expression of Uncertainty in Measurement, First edition 1993. International Organization for Standardization, Geneva92-67-10188-9 (corrected and reprinted 1995).

Brady, N.C., Weil, R.R., 2008. The Nature and Properties of Soils, Fourteenth ed. Pearson Prentice Hall, New Jersey, USA.

Cassidy, D.P., Werkema Jr., D.D., Sauck, W., Atekwana, E., Rossbach, S., Duris, J., 2001. The effects of LNAPL biodegradation products on electrical conductivity measurements. Journal of Environmental and Engineering Geophysics 6, 47-52.

Cozzarelli, I.M., Bekins, B.A., Baedecker, M.J., Aiken, G.R., Eganhouse, R.P., Tuccillo, M.E., 2001. Progression of natural attenuation processes at a crude oil spill site:I Geochemical evolution of the plume. Journal of Contaminant Hydrology 53, 369-385.

Davis, C.A., Atekwana, E., Atekwana, E., Slater, L.D., Rossbach, S., Mormile, M.R., 2006. Microbial growth and biofilm formation in geologic media is detected with complex conductivity measurements. Geophysical Research Letters 33, L18403. http://dx.doi.org/10.1029/2006 GL027312.

De Endredy, A.S., 1963. Estimation of free iron oxides in soils and clays by photolytic method. Clay Minerals Bulletin 9, 209-217.

Degans, B.P., 1997. Macro-aggregation of soils by biological binding mechanisms and the factors affecting these: a review. Australian Journal of Soil Research 35 , 431-459.

Forster, J.C., 1998. Soil Physical Analysis. In: Alef, K., Nannipieri, P. (Eds.), Methods in Applied Soil Microbiology and Biochemistry. Academic Press, London.

Gorby, Y.A., Yanina, S., McLean, J.S., Rosso, K.M., Moyles, D., Dohnalkova, A., Beveridge, T.J., Chang, I.S., Kim, B.H., Kim, K.S., Culley, D.E., Reed, S.B., Romine, M.F., Saffarini, D.A., Hill, E.A., Shi, L., Elias, D.A., Kennedy, D.W., Pinchuk, G., Watanabe, K., Ishii, S., Logan, B., Nealson, K.H., Fredrickson, J.K., 2006. Electrically conductive bacterial nanowires produced by Shewanella oneidensis strain MR-1 and other microorganisms. Proceedings of the National Academy of Sciences of the United States of America 103, 11358-11363.

Heinaru, E., Merimaa, M., Viggor, S., Lehiste, M., Leito, I., Truu, J., Heinaru, A., 2005. Biodegradation efficiency of functionally important populations selected for bioaugmentation in phenol- and oil-polluted área. FEMS Microbiology Ecology 51, 363-373.

Jonathan, P.A., Estella, A.A., Eliot, A.A., Joseph, W.D., Werkema, D.D., Silvia, R., 2007. The microbial community structure in petroleum-contaminated sediments corresponds to geophysical signatures. Applied and Environmental Microbiology 2860-2870. http://dx.doi.org/10.1128/AEM.01752-06.
Keevil, N.B., Ward, S.H., 1962. Electrolyte activity:its effect on induced polarization. Geophysics 27, 677-690.

Kemna, A., Binley, A., Slater, L., 2004. Crosshole IP imaging for engineering and environmental applications. Geophysics 69, 97-107.

KI (Keithley Instruments, Inc.), 1999. Model 2000 Multimeter User's Manual, 2000 900-01 Rev. F, Cleveland, Ohio, USA.

KI (Keithley Instruments, Inc.), 2005. Model 6220 DC Current Source, Model 6221 AC and DC Current Source, User's Manual, 622x-900-01 Rev. B, Cleveland, Ohio, USA

Klein, J.D., Sill, W.R., 1982. Electrical properties of artificial clay-bearing sandstones. Geophysics 47, 1593-1605.

Lesmes, D.P., Friedman, S.P., 2005. Relationships between the electrical and hydrogeological properties of rocks and soils. In: Rubin, Y., Hubbard, S.S. (Eds.) Hydrogeophysics, pp. 87-128.

Lin, T., Pan, P., Cheng, S., 2010. Ex situ bioremediation of oil-contaminated soil. Journal of Hazardous Materials 176, 27-34.

Marin, J.A., Hernandez, T., Garcia, C., 2005. Bioremediation of oil refinery sludge by landfarming in semiarid conditions: Influence on soil microbial activity. Environmental Research 98, 185-195.

Marshall, D.J., Madden, T.R., 1959. Induced polarization, a study of its causes. Geophysics $24,790-816$.

Martienssen, M., Reichel, O., Schirmer, M., 2003. Use of surfactants to improve the biological degradability of petroleum hydrocarbons. Chemie Ingenieur Technik 75, 1749-1755. http://dx.doi.org/10.1002/cite.200300056.

Martinho, E., Abreu, M.M., Pampulha, M.E., Alegria, F., Oliveira, A., Almeida, F., 2010. An experimental study of the diesel biodegradation effects on soil biogeophysical parameters. Water, Air, and Soil Pollution 206, 139-154. http://dx.doi.org/10.1007/ s11270-009-0092-y.

Naudet, V., Revil, A., 2005. A sandbox experiment to investigate bacteria-mediated redox processes on self-potential signals. Geophysical Research Letters 32, L11405. http://dx.doi.org/10.1029/2005 GL022735.

Ntarlagiannis, D., Ferguson, A., 2009. SIP response of artificial biofilms. Geophysics 74 A1-A5.

Ntarlagiannis, D., Williams, K.H., Slater, L., Hubbard, S., 2005. Low-frequency electrical response to microbial induced sulfide precipitation. Journal of Geophysical Research 110, G02009. http://dx.doi.org/10.1029/2005JG000024.

Oades, J.M., Jenkinson, D.S., 1979. Adenosine triphosphate content of the soil microbial biomass. Soil Biology and Biochemistry 11, 201-204.

Olhoeft, G.R., 1985. Low-frequency electrical properties. Geophysics 5, 2492-2503.

Oliveira, A., Pampulha, M.E., 2006. Effects of long-term heavy metal contamination on soil microbial characteristics. Journal of Bioscience and Bioengineering 102 157-161.

Orellana, E., 1982. Prospeccion Geoelectrica en Corriente Contínua. Paraninfo, Madrid (278 pp.).

Personna, Y.R., Ntarlagiannis, D., Slater, L., Yee, N., O'Brien, M., Hubbard, S., 2008 Spectral induced polarization and electrodic potential monitoring of microbially - Mediated iron sulphide transformations. Journal of Geophysical Research, Biogeosciences 113, G02020.

Póvoas, I., Barral, M.F., 1992. Métodos de análise de solos. Comunicações do Instituto de Investigação Científica Tropical: Série de Ciências Agrárias, 10. Instituto de Investigação Científica Tropical, Lisboa.

Reynolds, J.M., 1997. An Introduction to Applied and Environmental Geophysics. John Wiley \&Sons Ltd.

Sauck, W.A., 2000. A model for the resistivity structure of LNAPL plumes and their nvirons in sandy sediments. Journal of Applied Geophysics 44,151-165.

Sauck, W.A., Atekwana, E.A., Nash, M.S., 1998. Elevated conductivities associated with an LNAPL plume imaged by integrated geophysical techniques. Journal of Environmental and Engineering Geophysics 2, 203-212.

Schwertmann, U., 1964. Differenzierung der Eisenoxide des Bodens. Z. Planzenernährung, Düngung. Bodenkund 105, 194-202.

Sharma, P.V., 1997. Environmental and Engineering Geophysics. Cambridge University Press, Cambridge.

Six, J., Bossuyt, H., Degryze, S., Denef, K., 2004. A history of research on the link between (micro) aggregates, soil biota, and soil organic matter dynamics. Soil and Tillage Research 79, 7-31.

Slater, L., Ntarlagiannis, D., Personna, Y.R., Hubbard, S., 2007. Pore-scale spectral induced polarization signatures associated with FeS biomineral transformations. Geophysical Research Letters 34, L21404. http://dx.doi.org/10.1029/2007 GL031840.

Speir, T.W., Ross, D.J., 2002. Hydrolytic enzyme activities to assess soil degradation and recovery. In: Burns, R.G., Dick, R.P. (Eds.), Enzymes in the Environment. Activity, Ecology and Applications. Marcel Dekker, New York, Basel, pp. 407-433.

Tabatabai, M.A., 1982. Soil Enzymes. In: Page, A.L. (Ed.), Methods of Soil Analysis, Part 2. Agronomy monograph, vol. 9. American Society of Agronomy, Madison, Wisconsin, pp. 903-904

Tate, K.R., Jenkinson, D.S., 1982. Adenosine triphosphate measurement in soil: an improved method. Soil Biology and Biochemistry 14, 331-335.

Vanhala, H., 1997. Mapping oil-contaminated sand and till with the spectral induced polarization (SIP) method. Geophysical Prospecting 45, 303-326.

Vinegar, H.J., Waxman, M.H., 1984. Induced polarization of shaly sands. Geophysics 48, 1267-1287.

Williams, K.H., Ntarlagianni, D., Slater, L., Dohnalkova, A., Hubbard, S.S., Banfield, J.F., 2005. Geophysical imaging of stimulated microbial biomineralization. Environmenta Science and Technology 39, 7592-7600. 